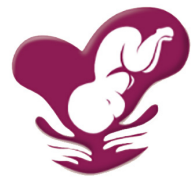

Published By: PERINASIA The Indonesian Society of Perinatology

\section{Characteristics of pregnancy with Systemic Lupus Erythematosus (SLE) in Dr. Mohammad Hoesin Hospital, Palembang}

CrossMark

Nyimas Aliyah Faizatun Muthmainnah ${ }^{1 *}$, Nuswil Bernolian ${ }^{2}$, Eddy Roflin ${ }^{3}$, Cindy Kesty ${ }^{2}$

'Medical Study Program, Faculty of Medicine, Universitas Sriwijaya, Palembang, Indonesia

${ }^{2}$ Department of Obstetric and Gynecology, Faculty of Medicine, Universitas Sriwijaya, Palembang, Indonesia

${ }^{3}$ Department of Public Health, Faculty of Medicine, Universitas Sriwijaya, Palembang, Indonesia

\section{*Corresponding to:}

Nyimas Aliyah Faizatun Muthmainnah; Medical Study Program, Faculty of Medicine, Universitas Sriwijaya, Palembang, Indonesia; nyimasaliyahf@gmail.com

\section{Received: 2020-11-02}

Accepted: 2021-01-30

Published: 2021-02-26

\section{ABSTRACT}

Background: Systemic Lupus Erythematosus (SLE) is an autoimmune disease with complex pathogenesis with broad clinical manifestations, more common in women of reproductive age between $15-44$ years, so there is an increased incidence in pregnancies.

Methods: This study was a descriptive observational study with a cross-sectional design using medical records of patients in Dr. Mohammad Hoesin Hospital Palembang from January 2018-June 2020. Sampling was carried out by total sampling with the presentation of data in tables and narratives. Data processing was performed using SPSS 25.

Results: There were 1,039 pregnancies in January 2018-June 2020 with 26 pregnancies with SLE and 8 patients (30.8\%) of moderate degree SLE. The demographic characteristics were $26-30$ age range (30.8\%), high school education status (53.8\%), the number of pregnancies $2-3$ times (53.8\%), the number of primiparous births (46.2\%), and the number of miscarriages was never experienced (65.4\%). Based on clinical signs and symptoms, malaise (15.4\%), malar rash, photosensitivity spots and alopecia (15.4\%), inflammatory arthritis (46.2\%), lupus nephritis (11.5\%), abdominal pain (34.6\%), lymphadenopathy (3.8\%), anemia or lymphopenia (15.4\%), and cephalgia (7.7\%). Meanwhile, the parameter of diagnosis was lymphopenia (15.4\%), eGFR stage 1 (34.6\%), proteinuria or proteinuria and cylindruria (11.5\%), ANA test (+) (19.2\%), anti-dsDNA test (+) (19.2\%), and the complement test decreased (7.7\%). Pregnancy outcomes were found to have intrauterine growth restriction (IUGR) (19.2\%) and preeclampsia and IUGR (11.5\%).

Conclusion: From the 26 pregnant patients with SLE, most were found with a moderate degree. Most demographic characteristics were age range 26-30 years old, high school education status, number of pregnancies 2-3 times, primipara, and never miscarriage. Characteristics of clinical signs and symptoms most commonly found in patients were malaise, malar rash, photosensitivity spots and alopecia, inflammatory arthritis, and abdominal pain. The diagnosis parameters were lymphopenia, stage 1 eGFR, proteinuria or proteinuria and cylindruria, ANA test (+), and anti-dsDNA test (+). Most pregnancy outcome is intrauterine growth restriction (IUGR).

Keywords: Systemic Lupus Erythematosus, Pregnancy, Intrauterine Growth Restriction.

Cite This Article: Muthmainnnah, N.A.F., Bernolian, N., Roflin, E., Kersty, C. 2021. Characteristics of pregnancy with Systemic Lupus Erythematosus (SLE) in Dr. Mohammad Hoesin Hospital, Palembang. Indonesian Society Of Perinatology 2(1): 12-19. DOI: 10.51559/inajperinatol.v1i2.10

\section{BACKGROUND}

Systemic lupus erythematosus (SLE) is an autoimmune disease with complex pathogenesis that can damage the body's organs with broad and intermittent clinical manifestations. SLE's risk ratio in women and men is 15: 1 to $22: 1$, which means that SLE is more common in women, especially in women of reproductive age between 1544 years. $^{1,2}$

Based on this, there is an increased incidence of pregnancy with SLE. SLE patients who experience remission more than six months before pregnancy have a $25 \%$ risk of exacerbations during pregnancy and $90 \%$ of good pregnancy outcomes, whereas in patients whose remission period is SLEs than six months, the risk of exacerbations is $50 \%$ during pregnancy and have poor pregnancy outcome. If a pregnancy occurs while the SLE is active, the risk of fetal death will increase to between $50-75 \%$ and the maternal mortality rate to $10 \%{ }^{3}$

In pregnancy with SLE, it is necessary to distinguish between a clinical symptom of the disease and a physiological change during pregnancy because they are similar to SLE clinical symptoms, so that the diagnosis of SLE in pregnancy is increasingly difficult to establish early, as in normal pregnancy, the changes obtained are flush facial, palmar erythema, postpartum hair loss, arthralgia and myalgia, anemia and mild thrombocytopenia. The active SLE clinical symptoms may include photosensitivity spots and oral or nasal ulcers, inflammatory arthritis, leukopenia or lymphopenia, as well as immune hemolytic anemia and thrombocytopenia. ${ }^{4}$

The risk of maternal and fetal complications will increase if, during pregnancy with SLE in conditions of a 
lupus flare, active disease, significant proteinuria or lupus nephritis, and antiphospholipid antibodies glucocorticoid therapy as well as with chronic hypertension, preeclampsia, or both., ${ }^{4,5}$

Increased cases of pregnant women with SLE have been recorded in several hospitals in Indonesia, but there is no data at Dr. Mohammad Hoesin Hospital (MHH), which has been published. Therefore, researchers are interested in researching pregnant women with SLE. Aspects to be studied include prevalence, description of clinical signs and symptoms, description of laboratory tests, pregnancy outcome with SLE, and the impact of pregnancy with SLE on the fetus. The data used in this study is secondary data, namely medical record data from pregnant women patients with SLE at MHH during the period from January 2018 to June 2020.

\section{METHOD}

This research is a descriptive observational study with a cross-sectional design to determine pregnant women's characteristics with SLE. This research was conducted from September to November 2020 in the Medical Staff Group (MSG) of Obstetrics and Gynecology at Dr. Mohammad Hoesin Hospital (MHH) and the Medical Records Casemix Division of MHH. Sampling was carried out by total sampling, i.e., all population units that met the inclusion criteria were taken as a sample unit with the inclusion criteria, namely patients aged 15-44 years, and the required variable SLE were recorded in the medical records.

Data collection was carried out unexpectedly following the SLE given by officers at the Obstetrics and Gynecology MSG and the MHH Medical Records Division. Each medical record provided by the officer, one by one, will be recorded or inputted by a third party on the computer until the entire population unit has been inputted.

Data processing was performed using computer assistance with Microsoft Excel and Statistical Package for Social Science (SPSS) 25.

Data analysis to describe the pregnancy characteristics of patients diagnosed with SLE at MHH was carried out descriptively. Data are presented in tabular and narrative form.
Table 1. Prevalence of pregnant patients with SLE

\begin{tabular}{lccc}
\multicolumn{1}{c}{ Period (Years) } & $\begin{array}{c}\text { Number of } \\
\text { Pregnancy per } \\
\text { Year }\end{array}$ & $\begin{array}{c}\text { Number of } \\
\text { Pregnant Patients } \\
\text { with SLE }\end{array}$ & $\begin{array}{c}\text { Percentage } \\
\text { (\%) }\end{array}$ \\
\hline January s.d December 2018 & 501 & 10 & $2.0 \%$ \\
January s.d December 2019 & 390 & 10 & $2.6 \%$ \\
January 2020 s.d June 2020 & 148 & 6 & $4.1 \%$ \\
\hline Total & 1.039 & 26 & $2.5 \%$ \\
\hline
\end{tabular}

Table 2. SLE disease activity scoring

\begin{tabular}{lcc}
\multicolumn{1}{c}{$\begin{array}{c}\text { Stage of Disease (based on the SLEDAI } \\
\text { scoring system) }\end{array}$} & Total (n) & Percentage (\%) \\
\hline No disease activity (score 0) & 3 & $11.5 \%$ \\
SLE with mild disease activity (scores 1-5) & 7 & $26.9 \%$ \\
SLE with moderate disease activity (score 6-10) & 8 & $30.8 \%$ \\
SLE with severe disease activity (score 11-19) & 5 & $19.2 \%$ \\
SLE with very severe disease activity (score $\geq 20)$ & 1 & $3.8 \%$ \\
Cannot be assessed & 2 & $7.7 \%$ \\
\hline Total & 26 & $100 \%$ \\
\hline
\end{tabular}

Table 3. Distribution of Demographic Characteristics Distribution

\begin{tabular}{|c|c|c|}
\hline Demographic Characteristics & Total (n) & Percentage (\%) \\
\hline \multicolumn{3}{|l|}{ Age } \\
\hline 15-20 years & 1 & $3.8 \%$ \\
\hline $21-25$ years & 4 & $15.4 \%$ \\
\hline $26-30$ years & 8 & $30.8 \%$ \\
\hline $31-35$ years & 7 & $26.9 \%$ \\
\hline $36-40$ years & 6 & $23.1 \%$ \\
\hline 41-44 years & 0 & $0 \%$ \\
\hline Total & 26 & $100 \%$ \\
\hline \multicolumn{3}{|l|}{ Education } \\
\hline Primary School & 1 & $3.8 \%$ \\
\hline JHS & 1 & $3.8 \%$ \\
\hline SHS & 14 & $53.8 \%$ \\
\hline University & 5 & $19.2 \%$ \\
\hline Total & 21 & $80.8 \%$ \\
\hline \multicolumn{3}{|l|}{ Number of Pregnancy } \\
\hline Primigravida & 5 & $19.2 \%$ \\
\hline 2-3 times & 14 & $53.8 \%$ \\
\hline 4-5 times & 6 & $23.1 \%$ \\
\hline $6-7$ times & 0 & $0 \%$ \\
\hline$>7$ times & 1 & $3.8 \%$ \\
\hline Total & 26 & $100 \%$ \\
\hline \multicolumn{3}{|l|}{ Number of Births } \\
\hline Nulipara & 7 & $26.9 \%$ \\
\hline Primipara & 12 & $46.2 \%$ \\
\hline Multipara & 7 & $26.9 \%$ \\
\hline Total & 26 & $100 \%$ \\
\hline
\end{tabular}




\section{RESULT}

This study uses secondary data from medical records of patients diagnosed as pregnant with SLE at Dr. Hospital.

Table 4. Distribution of Symptoms and Clinical Signs. Constitutional

\begin{tabular}{lcc}
\hline \multicolumn{1}{c}{$\begin{array}{c}\text { Characteristics of Symptoms and Clinical Signs } \\
\text { (Constitutional Symptoms) }\end{array}$} & Total (n) & Percentage (\%) \\
\hline Fatigue & 1 & $3,8 \%$ \\
Malaise & 4 & $15,4 \%$ \\
Malaise and weight loss & 1 & $3,8 \%$ \\
Malaise and fever (without evidence of infection) & 1 & $3,8 \%$ \\
Fever (without evidence of infection) & 1 & $3,8 \%$ \\
Weight loss & 1 & $3,8 \%$ \\
No symptoms & 17 & $65,4 \%$ \\
\hline Total & 26 & $100 \%$ \\
\hline
\end{tabular}

Table 5. Distribution of Mucocutaneous Symptoms and Clinical Signs

\begin{tabular}{lcc}
\multicolumn{1}{c}{$\begin{array}{c}\text { Characteristics of Symptoms and Clinical Signs } \\
\text { (Mucocutaneous) }\end{array}$} & Total (n) & $\begin{array}{c}\text { Percentage } \\
\text { (\%) }\end{array}$ \\
\hline Malar rash & 1 & $3,8 \%$ \\
Discoid rash & 0 & $0 \%$ \\
Photosensitivity patches & 0 & $0 \%$ \\
SLE mucous membranes (Oral or nasal ulcers) & 1 & $3,8 \%$ \\
Alopecia & 1 & $3,8 \%$ \\
Skin rash & 0 & $0 \%$ \\
Raynaud's phenomenon & 0 & $0 \%$ \\
Purpura & 0 & $0 \%$ \\
Urticaria & 1 & $3,8 \%$ \\
Vasculitis & 0 & $0 \%$ \\
Malar rash dan Alopecia & 2 & $7,7 \%$ \\
Malar rash, photosensitivity patches, and alopecia & 4 & $15,4 \%$ \\
Discoid rash, photosensitivity patches, mucous membrane SLEi \\
(oral or nasal ulcers), and alopecia & 1 & $3,8 \%$ \\
Malar rash, discoid rash, photosensitivity patches, mucous & 2 & $7,7 \%$ \\
membrane SLEi (oral or nasal ulcers) and alopecia & & \\
No symptoms & 13 & $50 \%$ \\
\hline Total & 26 & $100 \%$ \\
\hline
\end{tabular}

Table 6. Distribution of Musculoskeletal Symptoms and Clinical Signs

\begin{tabular}{lcc}
\multicolumn{1}{c}{$\begin{array}{c}\text { Characteristics of Symptoms and Clinical Signs } \\
\text { (Musculoskeletal) }\end{array}$} & Total (n) & Percentage (\%) \\
\hline Inflammatory arthritis & 12 & $46,2 \%$ \\
Polyarthritis & 1 & $3,8 \%$ \\
Arthralgia & 0 & $0 \%$ \\
Myositis & 0 & $0 \%$ \\
No symptoms & 13 & $50 \%$ \\
\hline Total & 26 & $100 \%$ \\
\hline
\end{tabular}

Of the 26 pregnant patients with SLE, 24 of them were assessed for disease activity, with the result that eight patients had a moderate degree of SLE with a percentage of $30.8 \%$ (Table 2).

Of the 26 patients, demographic characteristics were obtained, the most patients were in the age range 26-30 years, as many as eight patients (30.8\%) with an average age of 30 years with the youngest age 20 years and the oldest age 40 years. The educational status of the 26 patients, five of them did not have a history of education in the medical record data, so that of the 21 patients, it was found that the highest education status was high school (53.8\%) in 14 patients. In 14 pregnant patients with LES had 2-3 pregnancies (53.8\%), the number of primiparous births in 12 patients (46.2\%), and the number of miscarriages never experienced (65.4\%) in 17 patients (Table 3 ).

Symptoms and clinical signs in 26 patients were found to be mostly malaise in four patients (15.4\%) (Table 4).

The most mucocutaneous clinical signs and symptoms in 26 patients were malar rashes, photosensitivity spots, and alopecia in four patients (15.4\%) (Table 5).

In musculoskeletal clinical signs and symptoms, 12 out of 26 patients had inflammatory arthritis (46.2\%) (Table 6).

Data from 26 pregnant patients with LES found that three patients showed symptoms and clinical signs of kidney, known as lupus nephritis (11.5\%) (Table 7).

In gastrointestinal clinical signs and symptoms, the most common was abdominal pain complained of by nine patients (34.6\%) (Table 8).

Of the 26 patients, no patients (0\%) showed symptoms and clinical signs of the lungs, such as pleural abnormalities, lung parenchymal or pulmonary vascular lesions. None of the patients ( $0 \%)$ showed the presence of pericarditis, myocarditis or endocarditis. In reticuloendothelial clinical signs and symptoms, out of 26 patients, one patient had lymphadenopathy (3.8\%) (Table 9).

Of the 26 patients examined for hematology's clinical signs and symptoms, four had anemia or lymphopenia (15.4\%) (Table 10). 
Two out of 26 patients showed neuropsychiatric symptoms in cephalgia with unknown etiology (7.7\%) (Table 11).

Of the 26 patients, there were no patients $(0 \%)$ who experienced vascular clinical signs and symptoms in the form of venous and arterial thrombosis. There were no patients $(0 \%)$ who had ocular clinical signs and symptoms in the form of conjunctivitis.

In the parameters of diagnosis, of the 26 patients, only 24 patients had a supporting examination sheet on their

\section{Table 7. Distribution of Kidney Clinical Signs and Symptoms}

\begin{tabular}{lcc}
\hline Characteristics of Symptoms and Clinical Signs (Kidney) & Total (n) & $\begin{array}{c}\text { Percentage } \\
\text { (\%) }\end{array}$ \\
\hline Hematuria & 0 & $0 \%$ \\
Proteinuria & 1 & $3,8 \%$ \\
Cylindruria & 0 & $0 \%$ \\
Nephrotic syndrome & 0 & $0 \%$ \\
Kidney failure & 0 & $0 \%$ \\
Lupus nephritis & 3 & $11,5 \%$ \\
Proteinuria and cylindruria & 1 & $3,8 \%$ \\
Hematuria and proteinuria & 1 & $3,8 \%$ \\
Hematuria, proteinuria, and lupus nephritis & 1 & $3,8 \%$ \\
Proteinuria, cylindruria, and lupus nephritis & 2 & $7,7 \%$ \\
No symptoms & 17 & $65,4 \%$ \\
\hline Total & 26 & $100 \%$ \\
\hline
\end{tabular}

Table 8. Distribution of Gastrointestinal Symptoms and Clinical Signs

\begin{tabular}{lcc}
\multicolumn{1}{c}{$\begin{array}{c}\text { Characteristics of Symptoms and Clinical Signs } \\
\text { (Gastrointestinal) }\end{array}$} & Total (n) & Percentage (\%) \\
\hline Anorexia & 0 & $0 \%$ \\
Nausea & 3 & $11,5 \%$ \\
Vomiting & 0 & $0 \%$ \\
Nausea and vomiting & 3 & $11,5 \%$ \\
Diarrhea & 0 & $0 \%$ \\
Abdominal pain & 9 & $34,6 \%$ \\
No symptoms & 11 & $42,3 \%$ \\
\hline Total & 26 & $100 \%$ \\
\hline
\end{tabular}

Table 9. Distribution of Reticuloendothelial Symptoms and Clinical Signs

\begin{tabular}{lcc}
\multicolumn{1}{c}{$\begin{array}{c}\text { Characteristics of Symptoms and Clinical Signs } \\
\text { (Reticuloendothelial) }\end{array}$} & Total (n) & $\begin{array}{c}\text { Percentage } \\
\text { (\%) }\end{array}$ \\
\hline Lymphadenopathy & 1 & $3,8 \%$ \\
Splenomegaly & 0 & $0 \%$ \\
Hepatomegaly & 0 & $0 \%$ \\
No symptoms & 25 & $96,2 \%$ \\
\hline Total & 26 & $100 \%$ \\
\hline
\end{tabular}

the anti-dsDNA test positive results in five patients (19.2\%), and the complement test results decreased in two patients $(7.7 \%)$ (Table 12).

In pregnancy outcomes, both maternal and fetal, the most common was preeclampsia, and fetal growth was stunted in three patients (11.5\%). Only the most fetal outcome was stunted fetal growth in five patients (19.2\%) (Table 13).

\section{DISCUSSION}

Based on the data obtained, the prevalence of pregnant patients recorded at $\mathrm{MHH}$ from January 2018 to June 2020 reached 1,039 pregnancies. Meanwhile, the prevalence of pregnant patients with SLE during that period was only 26 pregnancies, with a percentage of $2.5 \%$. Different things were reported in the study conducted by Khairani et al. at Dr. Kariadi Semarang, where there were $4 \%$ of pregnancies with SLE, 16 out of 422 patients in January 2013 December 2016. Based on these data, it can be concluded that the incidence of pregnancy with SLE is still small. This study is in line with research conducted by Prof. Handono Kalim et al., where the incidence of SLE is still minimal in Indonesia. ${ }^{1,6}$

In demographic characteristics, age is classified into six age group groups. Of the 26 pregnant patients with SLE, the most extensive age range for pregnant patients, SLE is in the age range 26-30 years. This research is in line with what is written in the book Diagnosis and Management of Systemic Lupus Erythematosus from the Recommendations of the Indonesian Rheumatology Society written by Sumariyono et al., where the onset and clinical symptoms of SLE generally appear mostly at the age of 21-30 years. In the study, patients' mean age was 30 years, with the highest age being 26 years, and the youngest age was 20 years, and the oldest was 40 years. $^{2}$

In the demographic characteristics of educational status, of the 26 pregnant patients with SLE, five of them did not have data on educational status. Of the 21 patients, the most educational status obtained from the patients was senior high school (SHS), namely 14 patients with $53.8 \%$. Contrary to Yanih in 2016, most 
SLE sufferers are university graduates, both public and private. ${ }^{7}$

Another characteristic of demographic data is the number of patient pregnancies. Of the 26 pregnant patients with SLE, 14 patients (53.8\%) were pregnant 2-3 times, making it the highest number of pregnancies. Khairani et al. in 2018 at Dr. Kariadi Semarang, where the highest number of pregnancies was in patients with SLE, namely 2-3 times the number of pregnancies. ${ }^{6}$

Data on the number of births were also obtained from the patient's medical records, where out of 26 patients, 12 patients (46.2\%) had given birth once or were primiparous. Different things were reported in the study of pregnancy characteristics with SLE conducted by Khairani et al. in 2018 at Dr. Kariadi Semarang. In that study, the highest number of births in patients with SLE was multiparous or patients who had given birth several times. ${ }^{6}$

Another critical data is the number of miscarriages. From the medical records of 26 patients, 17 patients had never experienced a miscarriage with a percentage of $65.4 \%$. From medical record data, most patients experience abortion at 7-8 weeks of gestation and 12-16 weeks of pregnancy because fetal death due to abortion in pregnant patients with SLE can increase by 2-3 times as written in the SLE book in Pregnancy by Akbar et al. by 2020 . Fetal mortality due to abortion

Table 10. Distribution of Symptoms and Clinical Signs of Hematology

\begin{tabular}{lcc}
\multicolumn{1}{c}{$\begin{array}{c}\text { Characteristics of Symptoms and Clinical Signs } \\
\text { (Hematology) }\end{array}$} & Total $(\mathbf{n})$ & $\begin{array}{c}\text { Percentage } \\
\text { (\%) }\end{array}$ \\
\hline Anemia & 4 & $15,4 \%$ \\
Hemolysis & 0 & $0 \%$ \\
Lupus anticoagulants & 0 & $0 \%$ \\
Leukopenia & 0 & $0 \%$ \\
Lymphopenia & 4 & $15,4 \%$ \\
Thrombocytopenia & 1 & $3,8 \%$ \\
Anemia, thrombocytopenia, and lymphopenia & 3 & $11,5 \%$ \\
Anemia, leukopenia, and lymphopenia & 1 & $3,8 \%$ \\
Anemia and lymphopenia & 3 & $11,5 \%$ \\
Anemia and thrombocytopenia & 3 & $11,5 \%$ \\
Anemia and leukopenia & 1 & $3,8 \%$ \\
Thrombocytopenia and lymphopenia & 1 & $3,8 \%$ \\
No symptoms & 5 & $19,2 \%$ \\
\hline Total & 26 & $100 \%$ \\
\hline
\end{tabular}

Table 11. Distribution of Symptoms and Clinical Signs of Neuropsychiatry

\begin{tabular}{lcc}
\hline $\begin{array}{c}\text { Characteristics of Symptoms and Clinical Signs } \\
\text { (Neuropsychiatry) }\end{array}$ & Total $(\mathbf{n})$ & Percentage (\%) \\
\hline Seizures & 0 & $0 \%$ \\
Psychosis & 0 & $0 \%$ \\
Cranial and peripheral neuropathy & 0 & $0 \%$ \\
Organic brain syndrome & 0 & $0 \%$ \\
Transverse myelitis & 0 & $0 \%$ \\
Cognitive impairment & 0 & $0 \%$ \\
Mood disorders & 0 & $0 \%$ \\
Cephalgia (whose etiology is not exact) & 2 & $7,7 \%$ \\
No symptoms & 24 & $92,3 \%$ \\
\hline Total & 26 & $100 \%$ \\
\hline
\end{tabular}

can be more solemn if a pregnant patient with SLE has secondary anti-phospholipid syndrome (APS), which can cause recurrent pregnancy loss in the patient three times or more. As in this study, one of the four patients suffering from SLE and APS experienced abortion three times in a row at 12-13 weeks of gestation., ${ }^{4,8}$

Constitutional clinical signs and symptoms are often encountered in patients. Namely, malaise complained of four patients with $15.4 \%$. More than one clinical symptom and signs in one patient, such as two patients whose medical records were recorded as follows: one patient (3.8\%) was noted to experience malaise and body loss, and one patient (3.8\%) experienced malaise. And fever (without evidence of infection). Manole et al. in 2011, which discussed the manifestations of SLE, which in that study revealed that the most common symptoms that can be found in SLE patients are malaise, fever, and weight loss. ${ }^{9}$

In gastrointestinal symptoms and clinical signs, the most commonly found is abdominal pain. Abdominal pain in normal pregnancy and pregnancy with SLE needs to be differentiated because gastrointestinal manifestations may result from SLE or therapy complications. ${ }^{10}$

In the pulmonary and cardiac clinical signs and symptoms, the patient did not find it. This study shows that the patients do not see medical complications affecting the lungs, such as a lupus flare in certain circumstances and organ failure risk. ${ }^{4}$ However, patients with lupus carditis were not described as pericarditis, myocarditis, or endocarditis. SLE involvement in the heart can affect the pericardium, myocardium and endocardium. In one study, pericarditis was estimated to affect $25 \%$ of patients with SLE at the time of disease onset or relapse, whereas myocarditis was less common. ${ }^{11}$

There was one patient who experienced lymphadenopathy. Lymphadenopathy can differentiate normal pregnancy, and SLE pregnancy due lymphadenopathy was specific for SLE. Besides, lymphadenopathy can also be a sign of flare of SLE, which can be confirmed with certainty if there is also an increase in the characteristics of the rash, arthritis, fever, and anti-dsDNA antibodies are present. ${ }^{8}$ 
Table 12. Distribution of Parameters for Diagnosis

\section{Parameters of the Diagnosis Enforcement}

Complete blood count examination An

\section{Results}

Hemolytic anemia

Anemia

Leukopenia

Lymphopenia

Thrombocytopenia

Anemia, thrombocytopenia, and lymphopenia

Hemolytic anemia, thrombocytopenia and lymphopenia

Anemia, leukopenia and lymphopenia

Anemia and lymphopenia

Anemia and thrombocytopenia

Anemia and leukopenia

Thrombocytopenia and lymphopenia

Hemolytic anemia and thrombocytopenia

There is no check sheet

Normal

\begin{tabular}{|c|c|c|c|}
\hline \multirow{2}{*}{\multicolumn{2}{|c|}{ Total }} & \multirow{3}{*}{$\begin{array}{c}26 \\
9\end{array}$} & \multirow{3}{*}{$\begin{array}{l}100 \% \\
34,6 \%\end{array}$} \\
\hline & & & \\
\hline Kidney function tests: & Stage 1 & & \\
\hline \multirow[t]{7}{*}{ Estimated Glomerular Filtration Rate (eGFR) } & Stage 2 & 2 & $7,7 \%$ \\
\hline & Stage $3 a$ & 0 & $0 \%$ \\
\hline & Stage $3 b$ & 0 & $0 \%$ \\
\hline & Stage 4 & 0 & $0 \%$ \\
\hline & Stage 5 & 0 & $0 \%$ \\
\hline & There is no check sheet & 2 & $7,7 \%$ \\
\hline & Cannot be evaluated & 13 & $50 \%$ \\
\hline Total & & 26 & $100 \%$ \\
\hline \multirow[t]{6}{*}{ Urinalysis Examination } & Proteinuria & 3 & $11,5 \%$ \\
\hline & Cylindruria & 0 & $0 \%$ \\
\hline & Proteinuria and cylindruria & 3 & $11,5 \%$ \\
\hline & Normal & 13 & $50,0 \%$ \\
\hline & There is no check sheet & 2 & $7,7 \%$ \\
\hline & Not inspected & 5 & $19,2 \%$ \\
\hline Total & & 26 & $100 \%$ \\
\hline \multirow{4}{*}{$\begin{array}{l}\text { Immunology examination: } \\
\text { 1. Antinuclear Antibodies (ANA) Test }\end{array}$} & Positive & 5 & $19,2 \%$ \\
\hline & Negative & 1 & $3,8 \%$ \\
\hline & There is no check sheet & 2 & $7,7 \%$ \\
\hline & Not inspected & 18 & $69,2 \%$ \\
\hline Total & & 26 & $100 \%$ \\
\hline \multirow[t]{4}{*}{ 2. Anti-dsDNA } & Positive & 5 & $19,2 \%$ \\
\hline & Negative & 1 & $3,8 \%$ \\
\hline & There is no check sheet & 2 & $7,7 \%$ \\
\hline & Not inspected & 18 & $69,2 \%$ \\
\hline Total & & 26 & $100 \%$ \\
\hline \multirow[t]{5}{*}{ 3. Complement test (C3, C4, or $\mathrm{CH} 50)$} & Normal & 0 & $0 \%$ \\
\hline & Decline & 2 & $7,7 \%$ \\
\hline & Enhancement & 0 & $0 \%$ \\
\hline & There is no check sheet & 2 & $7,7 \%$ \\
\hline & Not inspected & 22 & $84,6 \%$ \\
\hline Total & & 26 & $100 \%$ \\
\hline
\end{tabular}

\section{Total (n) Percentage (\%)}

$0 \quad 0 \%$

$3 \quad 11,5 \%$

$0 \quad 0 \%$

$4 \quad 15,4 \%$

$1 \quad 3,8 \%$

$2 \quad 7,7 \%$

$1 \quad 3,8 \%$

$1 \quad 3,8 \%$

$3 \quad 11,5 \%$

$2 \quad 7,7 \%$

$1 \quad 3,8 \%$

$1 \quad 3,8 \%$

$1 \quad 3,8 \%$

\section{$\%$} $8 \%$ $8 \%$ $8 \%$ \% $8 \%$ $\%$ 烈 
Table 13. Distribution of Maternal and Fetal Outcomes

\begin{tabular}{lcc}
\hline \multicolumn{1}{c}{ Variable of Maternal and Fetal } & Total (n) & Percentage (\%) \\
\hline Abortus & 0 & $0 \%$ \\
Sectio Caesarea & 2 & $7,7 \%$ \\
Preterm delivery & 0 & $0 \%$ \\
Preeclampsia & 0 & $0 \%$ \\
Preeclampsia and SFG & 3 & $11,5 \%$ \\
Stunted fetal growth (SFG) & 5 & $19,2 \%$ \\
Maternal and fetal death & 1 & $3,8 \%$ \\
Neonatal syndrome lupus erythematosus (SLE) & 0 & $0 \%$ \\
There were no problematic maternal and fetal outcomes & 1 & $3,8 \%$ \\
Lack of data & 14 & $53,8 \%$ \\
\hline Total & 26 & $100 \%$ \\
\hline
\end{tabular}

Common symptoms and clinical signs of hematology are anemia or lymphopenia. Anemia is found with mild thrombocytopenia in normal pregnancy; therefore, to differentiate it from pregnancy with SLE, a complement level examination is necessary. The results were confirmed for SLE if there was a decreased complement level. ${ }^{4}$

On a complete blood count, out of 24 patients, it was found that most complete blood counts were laboratory results that showed lymphopenia. Sumariyono et al. in 2019. One of the most laboratory manifestations is lymphopenia and can make it the difference between pregnancy with SLE and normal pregnancy. Lymphopenia was found to be significantly associated with the presence of lupus nephritis, high steroid doses, and cyclophosphamide administration., ${ }^{2,12}$

None of the patients had their renal function checked or glomerular filtration rate (GFR), so that the researchers conducted an assessment of kidney function using the equation formula Cockcroft and Gault using body weight (kg) and the patient's serum creatinine test results. From these calculations, nine patients showed stage one eGFR results. We confirm the diagnosis of lupus nephritis, it is necessary to examine the GFR, and the examination will show a decrease from the standard limit of 90 or more. In addition to GFR, other signs are to see the presence of hematuria and proteinuria. ${ }^{4,13}$

On urinalysis, only proteinuria or both (proteinuria and cylindruria) could be found in the patient. Six patients had proteinuria caused by physiological changes in pregnancy because the results were not $>300 \mathrm{mg} /$ day. Proteinuria in pregnancy with SLE can be found $>300$ $\mathrm{mg} /$ day. ${ }^{4}$

As for immunological examinations, only the ANA, anti-dsDNA, and complement tests were recorded in several patients' medical records from several examinations. From these data, it is known that the positive ANA test results, the positive anti-dsDNA test, and the decreased complement test results are the most common results found in patients undergoing immunological examinations. These tests are essential for diagnosing a pregnancy with SLE because the ANA test serum ANA antibody can be found in people with active SLE. The positive anti-dsDNA test results and decreased complement levels can differentiate between a normal pregnancy and an SLE pregnancy. The anti-dsDNA test can also be a marker of flares lupus that attack the kidneys or lupus nephritis in the medical record. Only one patient was diagnosed with lupus nephritis who gave positive anti-dsDNA examination results. In contrast, others did not, and some were negative. ${ }^{2,4}$

Preeclampsia and stunted fetal growth (SFG) were the most common finding in maternal and fetal outcomes. Both of them occurred in one severe preeclampsia patient with a history of previous hypertension and one patient with severe preeclampsia, a history of hypertension, accompanied by moderate degrees of SLE activity assessment. The stunted fetal growth was the most outcome with three SLE patients. According to a study conducted by Stanhope in 2012, where he stated that also to labor preterm and preeclampsia, lupus nephritis could also increase the risk of adverse fetal outcomes, namely stunted fetal growth. Pregnancy with SLE is a risky pregnancy because it can increase pregnancy complications 2-4 times. Therefore it is necessary to monitor the symptoms of hypertension and fetal growth. Pregnancy with SLE may be continued until term if there are no symptoms of hypertension or fetal growth restriction, or fetal distress., ${ }^{4,14}$

\section{CONCLUSION}

Of the 26 pregnant patients with SLE, most were encountered with moderate degrees. Most demographic characteristics are 2630 years old, high school education status, 2-3 times pregnancy, primiparous, and never abortion. Characteristics of clinical signs and symptoms, most commonly malaise, malar rash, photosensitivity spots, and alopecia, inflammatory arthritis and abdominal pain. The most diagnosis parameters were lymphopenia, stage 1 eGFR, proteinuria or proteinuria and cylindruria, ANA (+) test, and antidsDNA (+) test. The most considerable pregnancy outcome is stunted fetal growth (SFG).

\section{DISCLOSURE}

\section{FUNDING}

None

\section{ETHICAL STATEMENT}

Ethics approval has been obtained from the Ethics Committee, Faculty of Medicine, Universitas Sriwijaya, Palembang, Indonesia, prior to the study being conducted.

\section{AUTHOR CONTRIBUTIONS}

All authors who listed in this manuscript have contributed in designing and concepting the study frameworks, data analyzing, and preparing the publish manuscript. 


\section{CONFLICT OF INTEREST}

All authors declared no conflict of interest regarding this study.

\section{REFERENCE}

1. Kementerian Kesehatan. Situasi Lupus di Indonesia. Jakarta: Pusat Data dan Informasi Kementerian Kesehatan RI. 2017. Hal 1-3.

2. Sumariyono, et al. Rekomendasi Perhimpunan Reumatologi Indonesia: "Diagnosis dan Pengelolaan Lupus Eritematosus Sistemik". Jakarta: Perhimpunan Reumatologi Indonesia. 2019: 4-15.

3. Sarwono. Ilmu Kebidanan. Jakarta: Yayasan Bina Pustaka Sarwono Prawirohardjo. 2016.

4. Akbar MIA. SLE dalam Kehamilan. Surabaya: Airlangga University Press, Surabaya. 2020.

5. Cunningham FG. William Obstetric $24^{\text {th }}$ Edition: Systemic Lupus Erythematosus.
Amerika Serikat: McGraw-Hill Education. 2014.

6. Khairani N. Karakteristik Kehamilan dengan lupus eritematosus sistemik di RSUP Dr. Kariadi Semarang. J Kedokt Diponegoro. 2018;7(2): 1457-69.

7. Yanih I. Kualitas Hidup Penderita Systemic Lupus Erythematosus (SLE) Berdasarkan LupusQoL. Jurnal Berkala Epidemiologi. 2016;31(4):1-12.

8. Sammaritano LR, Branch DW, dan Salmon JE. Maternal-Fetal Medicine PrincipSLE and Practice: Pregnancy and Rheumatic Diseases. Philadelphia: ESLEvier. 2019.

9. Cojocaru M, Cojocaru IM, Silosi I, Vrabie CD. Manifestations of systemic lupus erythematosus. Maedica (Bucur). 2011;6(4):330-6.

10. Kirby, J. M. Abdominal manifestations of systemic lupus erythematosus: Spectrum of Imaging Findings. Can Assoc Radiol J. 2009;60(3): 121-32.
11. Kreps A, Paltoo K, McFarlane I. Cardiac manifestations in systemic lupus erythematosus: A case report and review of the literature. Am J Med Case Rep. 2018;6(9): 180-3.

12. Sobhy N, Niazy MH, Kamal A. Lymphopenia in systemic lupus erythematosus patients: Is it more than a laboratory finding? The Egyptian Rheumatologist. 2019;19: 1-3.

13. National Kidney Foundation. GFR (Glomerular Filtration Rate). New York: National Kidney Foundation. 2013.

14. Stanhope, T. J. Obstetric Nephrology: lupus and lupus nephritis in pregnancy. Clin Jam Soc Nephrol. 2012;9;7(12): 2089-96.

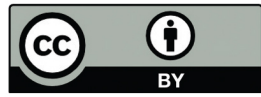

This work is licensed under a Creative Commons Attribution 